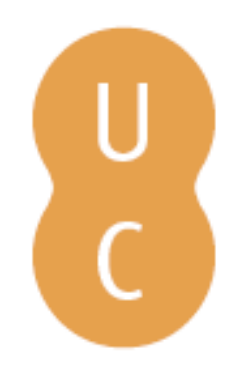

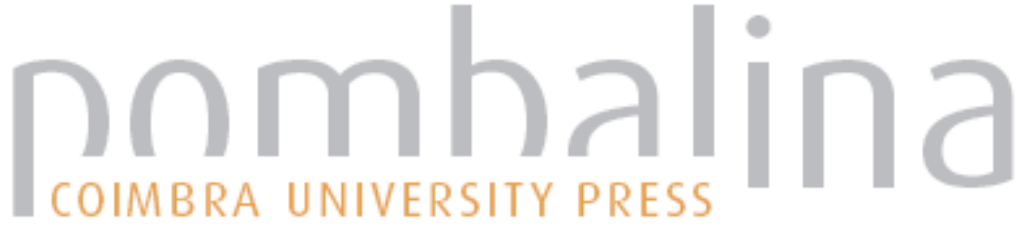

\section{Murilo Mendes: catolicismo primitivo / mentalidade moderna}

\author{
Autor(es): Santiago, Silviano
}

Publicado por: Imprensa da Universidade de Coimbra

URL

persistente: URI:http://hdl.handle.net/10316.2/42343

DOI: $\quad$ DOI:https://doi.org./10.14195/978-989-26-1308-6_32

Accessed : $\quad$ 26-Apr-2023 13:10:09

A navegação consulta e descarregamento dos títulos inseridos nas Bibliotecas Digitais UC Digitalis, UC Pombalina e UC Impactum, pressupõem a aceitação plena e sem reservas dos Termos e Condições de Uso destas Bibliotecas Digitais, disponíveis em https://digitalis.uc.pt/pt-pt/termos.

Conforme exposto nos referidos Termos e Condições de Uso, o descarregamento de títulos de acesso restrito requer uma licença válida de autorização devendo o utilizador aceder ao(s) documento(s) a partir de um endereço de IP da instituição detentora da supramencionada licença.

Ao utilizador é apenas permitido o descarregamento para uso pessoal, pelo que o emprego do(s) título(s) descarregado(s) para outro fim, designadamente comercial, carece de autorização do respetivo autor ou editor da obra.

Na medida em que todas as obras da UC Digitalis se encontram protegidas pelo Código do Direito de Autor e Direitos Conexos e demais legislação aplicável, toda a cópia, parcial ou total, deste documento, nos casos em que é legalmente admitida, deverá conter ou fazer-se acompanhar por este aviso.

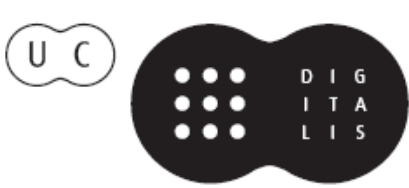





\section{MURILO MENDES: CATOLICISMO PRIMITIVO / M E N T A L I D A D E MO D ER NA}

Silviano Santiago

Resumo: Abordando a conversão ao catolicismo do poeta brasileiro Murilo Mendes, este ensaio debruça-se sobre as anotações do poeta e do seu amigo pintor Ismael Nery encontradas no livro Pèlerinages franciscains do escritor dinamarquês J. Joergensen. Aqui entendido como livro-relíquia (um livro dentro do livro), dele se parte para explorar relações intertextuais com a poética muriliana, que toma como sua base o desenvolvimento do sentido poético da vida, bem como o modelo franciscano de participação político-social cristã.

Palavras-chave: Murilo Mendes; catolicismo; conversão; anotações; S. Francisco de Assis; preocupação estética; preocupação teológica.

Abstract: An approach to the conversion to Catholicism of the Brasilian poet Murilo Mendes, this essay reads across the marginalia written by Murilo himself and his friend,the painter Ismael Nery, in the book Pèlerinages franciscains by Danish writer J. Joergensen. Taken as a relic-book (a book within a book), these marginalia lead to the exploration of 
intertextual relations to the poetics of Murilo, which stands on crucial questions such as the development of life's poetic meaning and the Franciscan model of Christian social and political involvement.

Keywords: Murilo Mendes; Catholicism; conversion; Saint Francis of Assis; aesthetic concerns; theological concerns.

A época em que [Ismael Nery] viveu era muito desfavorável ao catolicismo no Brasil. Os intelectuais eram, na grande maioria, agnósticos, comunistas ou comunizantes. Mesmo muitos com tendências espiritualistas disfarçavam-nas, por respeito humano. A religião aparecia-nos como qualquer coisa de obsoleto, definitivamente ultrapassada. O catolicismo era sinônimo de obscurantismo, servindo só para a base de reação.

Murilo Mendes, Recordações de Ismael Nery, I (1948)

Perseverança e acaso favorecem a redação destas anotações sobre o poeta Murilo Mendes nos primórdios da sua brilhante carreira.

Sempre julguei que a critica literária, ao ler e analisar a poesia de Murilo Mendes, passava ao largo da importância da conversão do poeta ao cristianismo. Refiro-me à conversão no sentido cristão do termo ${ }^{1}$ e não à inquietação religiosa, comum a outros poetas

${ }^{1} \mathrm{Em} \mathrm{1919}$, quando as enciclopédias religiosas ainda não listavam o verbete conversão, "o convertido Joseph Odelin não hesita ao reservar à fé cristã a palavra conversão". Define: "O que- é uma conversão? Cum vertere: virar, mudar, passar de uma falsa religião à verdadeira, da incredulidade à fé; passar da apostasia à vida cristã" (apud Gugelot). 
brasileiros e muitos, entre eles Mário de Andrade e Jorge de Lima. Vale dizer que os críticos e os historiadores não abordavam a originalidade maior da sua poesia dentro do primeiro Modernismo brasileiro.

Na verdade, Murilo deslocava o centro de atenção da ruptura estética insuflada pelos manifestos futuristas de Filippo Marinetti e pela vanguarda europeia que encaminhavam a literatura e as artes brasileiras modernas a uma postura construtivista e minimalista. Ao deslocar o fulcro do interesse pelo moderno no Brasil, Murilo o reorientava para dar-lhe forma inspirada na tradição do penitente medieval ${ }^{2}$ e no ideário político-social de São Francisco de Assis. Murilo difundia uma poética pessoal e única. Nela, a "fusão do catolicismo primitivo com a mentalidade moderna" (nos termos dele) dava origem a sintaxe inesperada e imagens complementares, paradoxais ou contraditórias.

Como não havia etiqueta vanguardista disponível para compreender os poemas comprometidos com a tradição medieval (em tempos onde domina a noção de ruptura estética) e com a visão cristã/ franciscana fusional (em tempos leigos), dizia-se que eles beiravam o ideário surrealista, embora este não servisse para explicá-los totalmente. E fiquei à espera.

$\mathrm{O}$ acaso colocou-me nas mãos o levantamento do acervo do poeta feito por Júlio Castañon Guimarães. Abro uma janela na listagem feita por ele e cito suas palavras: "Há casos curiosos [no acervo], como uma edição de 1922 de um livro intitulado Pèlerinages franciscains [Peregrinações franciscanas] (Joergensen), ${ }^{3}$ que apresenta anotações de duas pessoas, as de Murilo Mendes e as de seu grande amigo, o pintor Ismael Nery". Consta ainda do acervo, acrescenta

\footnotetext{
${ }^{2} \mathrm{Na}$ época, penitente é o que, para seguir o Cristo, vendia seus bens e adotava como modo de vida a reza, o jejum, a ajuda à igreja e a caridade.

${ }^{3}$ As traduções ao português são de minha responsabilidade.
} 
Júlio, "um desenho de Ismael Nery para a capa do primeiro livro de Murilo Mendes [Poemas], desenho que não chegou a ser usado". No livro lido por quatro olhos, cujas páginas estão sublinhadas por quatro mãos, descubro com espanto as palavras que Murilo deixou escritas:

Este livro contém à pgs. 175, 176 e 240, anotações de Ismael Nery e as suas iniciais autógrafas. // É um livro-relíquia. // Rio, 6.4.1934. // M.M. ${ }^{4}$

A condição de relíquia - preservada pelo convertido no dia exato da morte do Amigo - livra a escrita das peregrinações franciscanas dos golpes assassinos do tempo. Relíquia - informa-nos o Dicionário Houaiss - é "o que resta do corpo do santo", é "o nome dado aos objetos que pertenceram a um santo ou que tiveram contato com seu corpo".

Ao ter a persistência presenteada pelo acaso, resolvo intervir na bibliografia muriliana canônica, inaugurada de maneira auspiciosa por Mário de Andrade no célebre ensaio "A poesia em 1930",5 no qual o poeta juiz-de-forano sobressai como "surrealista" no grupo de quatro poetas, um experiente (Manuel Bandeira) e três estreantes (Carlos Drummond, Augusto Frederico Schmidt e Murilo). Em virtude de o livro de estreia de Murilo, Poemas, ser exemplo de dicção poética que escapa de modo surpreendente ao padrão imposto e legitimado pelos partidários da Semana de Arte Moderna (1922) é que Mário talvez o considere "historicamente o mais importante dos livros do ano".

\footnotetext{
${ }^{4}$ Tive acesso ao volume de Pèlerinages franciscains graças à gentileza da professora Nícea Nogueira, atual Diretora do Museu de Arte, em Juiz de Fora, e aos préstimos do colega e amigo Alexandre Faria. Meus agradecimentos.

5 Inserido posteriormente na coleção de ensaios intitulada Aspectos da literatura brasileira, hoje publicada pela Editora Itatiaia.
} 
O livro seguinte de Murilo, História do Brasil (1932), corrobora pelo avesso minha análise. Murilo se equivocou poeticamente ao querer deixar de ser seu contemporâneo para ser contemporâneo dos pares modernistas. História do Brasil apresenta poemas com dicção e temas tomados de empréstimo, por exemplo, da coleção Poesia Pau-Brasil (1924) e do Manifesto Antropófago (1928), ambos de Oswald de Andrade. Por decisão do autor, o livro de poemas publicado em 1932 não será republicado durante sua vida. Foi sumariamente excluído do volume que apresentava ao público sua obra poética reunida, Poesias - 1925-1955 (Mendes, 1959). Na "Advertência" que precede o conjunto dos livros até então esparsos, Murilo justifica o gesto radical:

Excluí as poesias satíricas e humorísticas que compõem a História do Brasil, pois, a meu ver, destoam do conjunto da minha obra; sua publicação aqui desequilibraria [grifo meu] o livro. O que se chamou de minha "fase brasileira" e "carioca" está suficientemente representado em algumas partes dos Poemas e em Bumba-meu-boi.

Não foi Murilo quem nos legou esta máxima: "A Igreja Católica é tão necessariamente verdadeira que eu preferiria errar com ela a acertar com os seus adversários"?

Hoje, quando o acervo pessoal de Murilo Mendes está depositado no Museu de Arte que leva o nome do poeta, localizado na cidade natal, Juiz de Fora, e dele dispomos para consulta, faz-se urgente contrabalançar o julgamento de Mário e retomar páginas de Sérgio Milliet no Diário crítico, datadas de 7 de fevereiro de 1942 (Milliet, 1981). Naquele dia, tendo por quadro a temática ampla da morte, Milliet elabora a busca do "anseio de unidade" que é entregue pela poesia de Murilo a todo e qualquer leitor. Segundo o crítico, o anseio de unidade leva o poeta "a voltar à fonte de vida porque dela 
fomos expulsos numa tremenda multiplicação". E acrescenta: "como um paleontologista que reconstitui o animal pelo osso encontrado, o poeta, com cada um dos fragmentos catados em sua caminhada, reforma a unidade primeira e primordial".

Apesar de não respaldar com exemplo o tratamento crítico do poeta como paleontólogo, Sérgio Milliet não poderia estar se referindo, entre outros, ao poema "A flecha" (Metamorfoses - 1938-1941)? Já o título do poema - transformado em metáfora (a flecha do tempo) - não traduziria e questionaria a evolução humana duma perspectiva linear? Naquele poema, em evidente delito contra o lugar-comum hegeliano, lemos: "Eis-me sentado à beira do tempo / Olhando o meu esqueleto / Que me olha recém-nascido". E seus versos finais não insistem no eterno-retorno sem diferença: "Na pedra que não se move / O motor do mundo avança"? Nas suas observações, Sérgio Milliet não estaria prenunciando "Ofício humano", belo poema de Poesia liberdade? Citemos: "As harpas da manhã vibram suaves e róseas. / O poeta abre seu arquivo o mundo -, / Vai retirando dele alegria e sofrimento / Para que todas as coisas passando pelo seu coração / Sejam reajustadas na unidade". Tudo isso não nos faz lembrar outro aforismo de Murilo: "O comunismo é revolucionário diante do capitalismo, e conservador diante do cristianismo"?

Escrito por Joergensen, o livro das peregrinações pela Itália franciscana é relíquia do amigo e artista Ismael Nery, falecido prematuramente de tuberculose no dia 6 de abril de 1934, assim como o é o poema "Meu novo olhar", escrito por Murilo Mendes e incluído no livro Tempo e eternidade (1934). Lemos nesse poema o sucedâneo da anotação aposta ao livro de Joergensen:

Meu novo olhar é o de quem assistiu à paixão e morte do Amigo, Poeta para toda a eternidade segundo a ordem de Jesus Cristo, E aquele que mudou a direção de meu olhar; 
É o de quem já vê se desenrolar sua própria paixão e morte,

Esperando a integração do próprio ser definitivo

Sob o olhar fixo e incompreensível de Deus. ${ }^{6}$

Durante os poucos anos de vida, Ismael foi também pródigo em homenagens ao poeta. Legou-nos o óleo Retrato de Murilo, a aguada Retrato do artista com Murilo e, possivelmente, o nanquim Composição surrealista.

A leitura do relato de viagem assinado por Joergensen e o poema "Meu novo olhar" atestam a conversão - "o novo olhar" - de Murilo por obra e graça de Ismael Nery, enterrado vestindo o hábito de terceiro-franciscano (é bom salientar) numa homenagem dos frades do Convento de Santo Antônio à sua ardente fé católica.

Em carta a Laís Correa de Araújo (1972), datada de 6 de abril de 1970, Alceu de Amoroso Lima (também conhecido pelo pseudônimo Tristão de Athayde) alerta para o equivoco perpetrado pela tradição historiográfica no tocante à conversão de Murilo e direciona o facho de luz da biógrafa e crítica mineira para a verdadeira atuação de cada um dos principais membros do grupo católico carioca. Salienta que o trabalho lento de conversão de Murilo à fé cristã foi provocado e apressado por Ismael Nery e informado pela preocupação estética (e não teológica). Murilo viera a conhecer o amigo em fins do ano de 1921 na seção de arquitetura e topografia do Patrimônio Nacional (Ministério da Fazenda). Escreve Alceu em 1970:

Gostaria muito de atender à sua solicitação quanto à circunstância da conversão do nosso Murilo Mendes. Acontece, porém, que essa conversão, creio eu, ocorreu antes do nosso primeiro

${ }^{6}$ Ler ainda o poema "Ismael Nery", em Tempo e eternidade, bem como as 17 crônicas escritas por Murilo sobre a amizade, hoje reunidas em Recordações de Ismael Nery (Mendes, 1995). 
encontro. Esse encontro, aliás, foi por assim dizer anônimo. . . . Creio que foi o seu convívio com Ismael Nery que provocou ou pelo menos apressou a conversão definitiva de Murilo. . . . Leonel Franca, ${ }^{7}$ creio eu, também teve influência na conversão de Murilo, que foi profunda e extremamente meditada. Não creio que tivesse tido nenhuma "iluminação" do tipo de [André] Frossard ou de [Paul] Claudel, mas um trabalho lento do tipo de [John Henry] Newman, embora do ponto de vista estético, sempre fundamental em Murilo, e não teológico. (Araújo 189-190)

O acaso é pródigo em associações reveladoras e, no presente caso, se alicerçado arqueológica e racionalmente no "livro-relíquia", ele nos fornece pistas para se chegar a um modelo europeu de metamorfose religiosa com vistas, por um lado, ao "desenvolvimento do sentido poético da vida" (apud O discípulo de Emaús, 1944, § 170) ${ }^{8}$ e, pelo outro, a modelo franciscano de participação político-social cristã. A solidariedade cristã, que "jamais fecha ao pobre o olhar e a bolsa" (v. A idade do serrote, 1968), era vetor desconhecido dos intelectuais e artistas modernistas brasileiros inclinados à esquerda. Como diz a epígrafe deste posfácio, julgavam o catolicismo como mero obscurantismo. Ao elencar a opção pelo legado franciscano, o modelo de conversão muriliano era também desconhecido da maioria dos católicos brasileiros que, na década de 1930, estarão por detrás

${ }^{7}$ Leonel Franca (1893-1948), jesuíta, professor no Colégio Santo Inácio, foi um dos fundadores da Pontifícia Universidade Católica do Rio de Janeiro e seu primeiro reitor.

${ }^{8}$ Se não for absuso da minha parte, há um trabalho a ser feito entre as relações entre Murilo Mendes e o historiador Jaime Cortesão (pai de sua esposa) por ocasião da sua passagem pelo Brasil no tocante a seus escritos "franciscanos" sobre os descobrimentos. 
dos valores elitistas e conservadores que norteiam o agrupamento Ação Católica, no Rio de Janeiro.?

A leitura do livro-relíquia traz para a cena carioca dois dinamarqueses convertidos, alguns escritores franceses e, principalmente, a tradição católica na arte italiana. Sob o efeito do solvente São Francisco de Assis (associado por Jorgensen a Santa Clara e a Santa Ângela de Foligno), os três elementos díspares precipitam na sala do Ministério da Fazenda, então localizado no Rio de Janeiro, e alimentam a sensibilidade fraterna e cristã dos dois brasileiros nos seus anos de formação. São Francisco de Assis é o diferencial. É a porta de entrada para modelo de conversão distinto do francês, que se alicerça mais no retiro espiritual e menos na peregrinação. ${ }^{10}$ Também extrapola o credo predominante no Brasil, derivado do ensino feito sob a responsabilidade das ordens dos jesuítas, dominicanos, etc.

Pode-se tentar rastrear o aparecimento do livro Pèlerinages franciscains no universo de Ismael e Murilo. Se não for de todo falsa a hipótese que levanto, ele surge nos primeiros anos da década de 1920 e representa o desassossego existencial que, como larvas, fiam vários casulos. Nestes, as "inquietações religiosas" (apud Alceu) comuns a vários artistas e intelectuais extraviados do caminho de Cristo - atuam como crisálidas que maturam o momento definitivo da afirmação subjetiva pela verdade. Se não for falsa a hipótese, o livro teria a ver com as duas viagens de estudo de Ismael a Paris, em particular com a primeira, devido ao fato de o jovem pintor ter-se matriculado em 1920 na Académie Julian, fundada pelo pintor

\footnotetext{
9 Para melhor conhecimento da matéria, aconselha-se a leitura do notável ensaio de Francisco Iglésias "Estudo sobre o pensamento reacionário de Jackson de Figueiredo" (1971). No tocante às manifestações literárias modernistas de teor cristão, consultar o livro Festa, de Neusa Pinsard Caccese (1971).

10 Para a distinção, seria útil a leitura de Gugelot, La Conversion des intellectuels.
} 
Rodolphe Julian, ${ }^{11}$ e de ter convivido com importantes artistas franceses e estrangeiros que lá aprimoravam sua arte.

Naquela Academia Ismael teve acesso à tradição pós-impressionista de vanguarda, representada desde os fins de 1880 pelos fundadores do grupo Nabis, ${ }^{12}$ que tinham em Gauguin o verdadeiro mestre. Nabis vem do hebreu navi, que significa profeta ou vidente e indicia o fato de que o grupo de artistas se exprimia pelo caráter sagrado da pintura. Na Academia, graças à projeção no meio artístico francês da arte italiana e do exemplo de São Francisco de Assis, Ismael pôde ter tido acesso a uma série de vidas modelares de convertidos franceses e estrangeiros. À p. 128 do livro-relíquia, lemos esta bela amostragem de proselitismo de Joergensen a favor da vida intelectual italiana e franciscana, ${ }^{13}$ então apreciada na França apenas pelos escritores que se reuniam em torno da Nouvelle Revue Française:

Ah! Itália, minha Itália. Cara Itália, como te vejo e te sinto e te amo! Será que conseguirei levar os compatriotas a compartilhar meu interesse por ti, a te compreender e a te amar como eu! De há muito a Alemanha ganhou seu lugar na nossa vida intelectual. Mais tarde, a França e a Inglaterra se aproximaram de nós. Mas

\footnotetext{
${ }^{11}$ Muitos estrangeiros se inscreveram na Academia. Entre os brasileiros, destaque para Georgina Albuquerque, Rodolfo Amoedo, Eliseu Visconti, Nicolina Vaz de Assis e Tarsila do Amaral, contemporânea de Ismael Nery na Academia. Em virtude de aceitar desde 1897 (ou 1873, segundo outras fontes) mulheres que pintavam a partir de nus masculinos, a Academia ganhou bons estudos nas últimas décadas. Seria bom que algum estudioso da arte brasileira desenhasse essa genealogia.

12 No grupo Nabis, destacam-se Pierre Bonnard, Maurice Denis, Édouard Vuillard, Félix Vallotton e o escultor Aristide Maillol. Costumavam terminar suas cartas com as iniciais E. T. P. M. V. et M. P. (Em ta paume, mon verbe et ma pensée - na palma da tua mão meu verbo e meu pensamento).

13 Contrastem-se a Itália do Futurismo e a de São Francisco. Em resposta à enquete "O mês modernista" (15/12/1925), Sérgio Milliet afirma: "O grito de Marinetti foi um alívio. O Ipiranga da literatura é na Itália”. Lá também ouve-se o grito de alforria de Murilo.
} 
será que durante nossa vida não haverá um espaço livre para a Itália, para essa autêntica, real, simples e profunda Itália que, noutro dia, no mosteiro de Fonte-Colombo, ${ }^{14}$ chamei de Itália franciscana! E será que me engano quando imagino que minha missão em vida consiste exclusivamente em levar meus compatriotas a conhecer essa Itália?

Naquela Academia, Ismael talvez tenha tomado conhecimento da intensa amizade entre o escritor dinamarquês Johannes Joergensen (1866-1956), autor do livro-relíquia, e um antigo estagiário na Académie Julian, Mogens Ballin (1871-1914), filho de importante família judia dinamarquesa, escultor e ourives especializado em prata e estanho que, no passado, tinha tomado aulas de pintura com a conterrânea Mette Sophie Gad, futura esposa de Gauguin, mestre dos Nabis. No ano de 1892, Ballin faz longa viagem à Itália e se converte ao catolicismo. No mês de janeiro de 1893, ele é batizado em Fiésole, na Toscana. Sabe-se que o encontro de Joergensen com o artista judeu convertido representa um marco na vida de ambos.

Embora fosse poeta e também tradutor de Charles Baudelaire e de Paul Verlaine, Joergensen, de família luterana, não tinha encontrado até então nas literaturas estrangeiras a profundidade espiritual que sua alma de artista buscava. Em 1894, por sugestão do seu amigo Mogens Ballin, decide visitar a Itália pela primeira vez. Os dois param na cidade de Assis. Fascinado pela forte impressão causada pelo encontro com a arquitetura e a arte italiana de fundo religioso e principalmente pelas leituras de e sobre São Francisco de Assis - como está dito na passagem que escolhemos para citar acima -, Joergensen se converte também ao cristianismo e abraça o amigo

${ }^{14}$ No Santuário de Fonte Colombo, São Francisco de Assis recebeu de Jesus, em 1223, a confirmação da ordem franciscana. 
recém-convertido. Daquele ano data sua devoção à vida e à obra de São Francisco de Assis.

Joergensen virá a narrar sua própria conversão em Livre de route (1898), inspirado no livro En route (1895), onde o romancista francês J.-K. Huysmans ${ }^{15}$ descreve sua própria conversão ao catolicismo ortodoxo, tendo como cenário o monastério da Trappe de Notre-Dame-d'Igny (França), fundado por São Bernardo em 1127. Leia-se, em particular, o quarto capítulo do livro de Huysmans. ${ }^{16}$ Em 1903, Joergensen será autor das Peregrinações franciscanas, cuja edição francesa é lida e anotada pelo artista Ismael e pelo poeta Murilo talvez no mesmo ano da Semana de Arte Moderna. A partir de 1915 Joergensen fixará residência na pequena cidade de Assis.

As páginas do exemplar de Pèlerinages franciscains trazem muitas das margens sublinhadas com linha vertical simples ou dupla, à esquerda ou à direita do texto. A linha vertical duplicada insiste na importância maior do trecho, como será o caso das sucessivas páginas consagradas à leitura por Joergensen da conversão de Santa Ângela de Foligno, tal como narrada pela penitente ao padre-confessor, Irmão Arnaud (pp. 184-189). ${ }^{17} \mathrm{O}$ exemplar traz ainda

15 Numa simples consulta à biblioteca de Murilo, hoje no Museu de Arte, constata-se a presença de quatro dos títulos do famoso romancista de $\grave{A}$ rebours (Às avessas, traduzido por José Paulo Paes).

${ }^{16}$ A descrição por Huysmans do ato de comunhão na Trappe guarda um deslizamento estranho e muriliano do sagrado para o profano, e vice-versa, como está em "O poeta na igreja" (Poemas). Vale a pena reproduzir o parágrafo: "A alma sofreu uma verdadeira síncope, perdeu a lucidez; e quando ela voltou a si, ele se espantou por não ter sentido uma comoção desconhecida de alegria; em seguida, ele ficou longo tempo a ruminar uma lembrança incômoda, todo o lado demasiadamente humano da deglutição de um deus; a hóstia recebida colou no céu da boca e, com a ajuda da língua, ele teve de procurá-la e enrolá-la como a uma panqueca para engoli-la". De Murilo lembre-se este aforismo: "Pelos cinco sentidos também se vai a Deus".

17 A propósito da conversão de Santa Ângela, leia-se a audiência em seu louvor feita pelo Papa Bento XVI no dia 13 de outubro de 2010 na Praça de São Pedro, em Roma. Vídeo disponível em: <http://vod.vatican.va/udienza13102010.mov>. Recentemente Santa Ângela volta ao contexto brasileiro, agora pela vontade do Papa 
inúmeros parágrafos sublinhados com linha horizontal. O conjunto dos sublinhados verticais e horizontais fascina e nos garante a escolha impulsiva, pertinente, delicada, amorosa ou reflexiva de certas passagens por Ismael e por Murilo. Como a assinatura de Ismael aparece apenas em três páginas, somos levados a crer que o substantivo das marcas de leitura pertence quantitativamente a Murilo. Nossa leitura não será, por sua vez, do livro assinado pelo escritor dinamarquês, cujos dados relevantes já foram fornecidos; será antes leitura-de-uma-leitura, leitura de livro dentro do livro. Leitura duma espécie de pequeno livro extraído do maior, que o consulente poderá imprimir para uso próprio caso some as páginas sublinhadas em vertical com as outras em que os parágrafos estão sublinhados em horizontal.

Leiamos Joergensen por uma das páginas sublinhadas por Ismael Nery, a de número 240. Ele sintoniza com o dinamarquês na cidade italiana de Cortona, no momento em que o peregrino visita o mosteiro de Celle. Lá, em 1221, São Francisco converte algumas figuras proeminentes, dentre elas Guido Vagnotelli, jovem rico e poderoso, que se dispõe a dar suas posses aos pobres. A conversão de Guido estará retratada no $37^{\circ}$ fioretti, que Joergensen lê em Cortona e Ismael admira e sublinha no Rio de Janeiro. ${ }^{18}$

A dupla leitura do fioretti salienta que Guido recebe o santo e seu companheiro "com grandíssima cortesia": "tinha abraçado e beijado amigavelmente o santo, e depois the havia lavado os pés e acendido um grande fogo e preparado a mesa com muito boas iguarias e, enquanto os dois companheiros comiam, os servia com um rosto cheio de alegria".

Francisco I. A canonização de Anchieta - chamada "equivalente", pois não se conhece milagre do beato jesuíta - tem a santa de Foligno como antecessora e garantia.

18 Leia-se o fioretti "Como Jesus Cristo bendito, a pedido de S. Francisco, fez converter-se um rico e gentil cavaleiro a fazer-se frade, o qual tinha feito grande honra e oferendas a S. Francisco". 
Vendo tanta cortesia e afabilidade, São Francisco concebe tal amor que o leva a julgar que o cavaleiro ganhou o direito de entrar para a Ordem. São Francisco justifica: Guido "é tão grato e reconhecido para com Deus e tão amorável e cortês para com o próximo e os pobres".

Aparece como inevitável o elogio da cortesia por São Francisco: "a cortesia é uma das propriedades de Deus, o qual dá seu sol e sua chuva aos justos e aos injustos por cortesia, e a cortesia é irmã da caridade, a qual extingue o ódio e conserva o amor". ${ }^{19}$

Sublinhada por Ismael, a passagem talvez tenha sido um dos fios condutores da leitura de Murilo. Insisto nessa hipótese porque a cortesia - tal como descrita e expressa no fioretti e é comentada por Joergensen e sublinhada por Ismael - é o valor religioso maior que retém e engloba muitas das qualidades sublinhadas por Murilo que se tornaram indispensáveis para que a vontade própria alavancasse o movimento radical da sua conversão.

Remeto o interessado à leitura de Pèlerinages franciscains e, por isso, apenas enumero, resumindo, os valores franciscanos sublinhados por Murilo no texto.

$O$ direito de ser pobre se fortalece num mundo em que a luta universal tem por objeto a riqueza e numa sociedade em que o valor do homem é julgado pelo ouro que possui. Talvez seja pelos ensinamentos de Santa Clara de Assis, fundadora das Damas Pobres (ou Clarissas), que Giotto tenha figurado a pobreza com a imagem duma mulher. A humildade extrai sua força do amor espiritual. Nos últimos dois séculos o mundo se tornou mais cristão, apesar de ter sido tomado pelas ideias iluministas. Maior se tornou o desejo de realizar o programa social de Jesus Cristo. O espírito franciscano

19 Na décima-primeira crônica de Recordações de Ismael Nery, escrita em 1948, Murilo comentará a leitura por Ismael do livro de Joergensen. Nem autor nem titulo do livro são mencionados, apenas a passagem acima rereferida. A edição moderna das recordações comportaria pelo menos essa nota explicativa. 
é essencialmente e antes de tudo o espírito de respeito à vida e a tudo que lhe é útil. Exemplo: por deferência, um homem tirava o chapéu quando passava pelo campo de trigo. A tristeza é um vício babilônico: elogio da alegria do espírito, da alegria espiritual. Contra os excessos: os do prazer e os da abstinência. De nada vale distribuir aos pobres sua riqueza sem o sentimento de amor. O amor suporta tudo, crê tudo, espera tudo, aceita tudo. Do ódio santo contra o mal nasce sempre o amor, não o amor dito em belas frases, mas o amor real que ardia no coração de São Francisco. Todos os homens devem ser irmãos. Por fome e por sede, clamar por Deus. Por fome de bondade e sede de santidade. Somos destinados à vida, à luz e ao céu. Verdade e amor. A salvação está na verdade, que se confunde com o amor. "Verdade e amor, nunca me abandonem".

Se a cortesia está no cerne do ideário franciscano de Ismael, talvez o pecado seja a figura religiosa mais visível na perspectiva tomada por Murilo. Leiam-se, por exemplo, as páginas 184-189, todas sublinhadas à margem por linhas verticais duplas. Nelas, Joergensen, tendo tomado assento diante do túmulo de Santa Ângela de Foligno, resume cuidadosamente a Via Crúcis de Jesus Cristo que - pelo avesso sofrido e doloroso - se enlaça erótica e místicamente, se me permitem os advérbios, à vida vaidosa e pecadora da futura convertida. Joergensen lê então a longa passagem do livro $A$ vida de Santa Ângela de Foligno, tal como escrita pelo irmão Arnaud. No trecho sublinhado, o pecado é motivo das orações e das lágrimas de Santa Ângela, por ter sido ele a principal causa da morte de Jesus. O pecado é sinal da ingratidão humana e se transforma em evidente e incontornável força do mal no momento em que Ângela vê o corpo crucificado de Jesus.

Não há dúvida que o contraste fulgurante e iluminador entre o mundano, obrigatoriamente pecaminoso no universo da convertida, e o espiritual, meta da Vida em Cristo, é também um dos temas 
maiores da poesia de Murilo $^{20}$ e não haverá exemplo mais concreto do caminho a ser percorrido pelo convertido que a leitura do caso de Santa Ângela tal como narrado por ela ao padre confessor. Joergensen nos transmite o ardor da convertida que chega a sentir nos ossos e juntas do próprio corpo todo o flagelo da paixão de Cristo. Murilo talvez tenha também ficado impressionado com a alta voltagem poética da linguagem de Santa Ângela, pois a ela retorna, agora em estudo publicado por Louis Lecleve, que ainda está na biblioteca de Murilo (Lecleve, 1936).

Pela comparação das partes do corpo humano e as do corpo espiritual de Jesus é que a questão conflitiva do pecado entra no texto da confissão e da conversão de Ângela. Despedaçadas como num tratado de anatomia, ${ }^{21}$ as partes do corpo feminino vaidoso se sucedem e são contrastadas com a versão paralela, sofrida e dilacerada, do corpo masculino de Cristo crucificado. O texto da futura convertida se organiza como que pelo paralelo entre duas planchas anatômicas. A medicina que minha metáfora invoca não é gratuita, já que, no texto, Cristo é o médico, o "médico espiritual". Ele é o portador do remédio (contrepoison, no texto) que, por sua vez, se confunde com seu próprio sangue derramado. ${ }^{22}$ Corpo e sangue de Cristo, a comunhão que resgata o pecado.

20 Como exemplo do contraste entre o corpo humano e o espiritual, leia-se "O poeta na igreja" e "Vidas opostas de Cristo e dum homem", em Poemas, ou "Poema espiritual", em A poesia em pânico. Na poesia de Murilo, muitas vezes o humano é o "mundo das formas" e o espiritual, "transparência". Vale a pena uma consulta ao repositório de imagens que representam Santa Ângela em êxtase, cuja ambiguidade semântica pode ser objeto de estudo.

${ }^{21}$ Belo exemplo retórico de despedaçamento do corpo está em "Corte transversal do poema" (Poemas): "Meu pensamento desloca uma perna, / o ouvido esquerdo do céu não ouve a queixa dos namorados. / Eu sou o olho dum marinheiro morto na Índia, / um olho, andando com duas pernas. / O sexo da vizinha espera a noite se dilatar, a força do homem. / A outra metade da noite foge do mundo, empinando os seios". Já o corpo feminino despedaçado fundamenta o poema "Jandira", em O visionário.

22 Cf. "Car il ne faut rien d'autre pour le salut que ce que le médecin exige du malade [. . .] mon âme acquit la compréhension du contrepoison qui réside dans 
O rosto mundano e maquiado de Ângela, que visava ao favor dos homens, se reflete no rosto santo de Cristo, escarrado, desfigurado e socado pelos homens. Os olhos vaidosos de Ângela contrastam com os olhos de Cristo que se cegaram pelas lágrimas e depois pelo sangue coagulado. As orelhas de Ângela, que se alegravam com a graça da vida fútil e inútil, são comparadas às orelhas divinas, que se calaram diante de acusações falsas, injúrias, sarcasmos. Ouviram em silêncio a sentença injusta de morte e, principalmente, o lamento da própria mãe. A boca de Ângela, que privou dos prazeres da mesa, se contrapõe à boca faminta e seca na cruz, aplacada com vinagre e fel. As imagens do corpo humano se estendem pelo texto, sempre em contraste: ombros que carregam a cruz, cravos nas mãos e nos pés, o coração trespassado por uma lança. Elas fulguram um corpo nu, como tinha saído do seio da Virgem. Às imagens do corpo se sucedem à imagem da dama que tudo teve e a de Jesus que sempre fora pobre.

\section{Obras citadas}

Andrade, M. de. Aspectos da literatura brasileira. São Paulo: Livraria Martins Editora, s.d. Print.

Araújo, L. C. de. Murilo Mendes. Petrópolis: Vozes, 1972. Print.

Caccese, N. P. Festa. São Paulo: IEB, 1971. Print.

Escritos de São Francisco. Trad. C. Márcio Teixeira. Petrópolis: Vozes, 2009. Print.

Gugelot, F. La Conversion des intellectuels au catholicisme en France - 1885-1935. Paris: CNRS, 1998. Print.

Huysmans, J. K. En route. Paris: Plon, 1965. Print.

Iglésias, F. "Estudo sobre o pensamento reacionário de Jackson de Figueiredo". In História e ideologia. São Paulo: Perspectiva, 1971. Print.

Joergensen, J. Pèlerinages franciscains. Trad. do francês de T. de Wizewa (com autorização do autor). Paris: Perrin, 1922. Print.

le sang du Christ". 
Le livre des visions et des instructions de la Bienheuse Angèle de Foligno, s.d. Trad. E. Hello. Web. 16 julho, 2015.

Lecleve, L. Sainte Angèle de Foligno. Paris: Plon, 1936. Print.

Mendes, M. Poesias - 1925-1955. Rio de Janeiro: José Olympio, 1959. Print.

Recordações de Ismael Nery. São Paulo: Edusp, 1995. Print.

Milliet, S. Diário crítico - I. São Paulo: Martins, 1981. Print.

O mês modernista. Estabelecimento do texto, comentários e notas de Homero Senna. Rio de Janeiro: Casa de Rui Barbosa, 1994. Print. 